\title{
ECONOMIA POLÍTICA DA ÁGUA NO BRASIL
}

Elizabeth Borelli ${ }^{1}$

\section{RESUMO}

Este texto tem por objetivo analisar o papel da água como insumo vital para a sobrevivência sob o olhar da economia política, a partir das relações entre produção, sociedade e meio ambiente. Na primeira parte do texto, o atual problema de escassez da água no mundo será tratado de forma descritiva; na segunda, será colocado o contexto da gestão da água no Brasil, numa ótica regional, e na terceira, serão discutidos alguns elementos críticos acerca dos instrumentos de gestão da água, a partir dos princípios da sustentabilidade ambiental. A temática dos recursos hídricos adquiriu grande abrangência social e política no decorrer das últimas três décadas, quando a questão da escassez da água passa a centralizar as preocupações mundiais com o meio ambiente, além dos problemas tradicionais, como desmatamento, degradação e poluição. Embora o Brasil não se encontre entre os países mais impactados pela escassez da água, a má distribuição regional das águas brasileiras configura um quadro de desigualdade ambiental. Por outro lado, a opulência do recurso

1 Professora do Programa de Estudos Pós-graduados em Economia Política da PUC-SP. Pesquisadora do Grupo de Pesquisas em Economia Industrial, Trabalho e Tecnologia. 
se configura num atrativo para o capital privado. Dessa forma, questiona-se até que ponto a apropriação privada da água, voltada ao lucro, não estaria restringindo o acesso da população à água, em benefício do capital.

Palavras-chave: Água; Escassez de água; Meio ambiente; Gestão da água.

\section{INTRODUÇÃO}

A crescente preocupação mundial com as reservas de água doce, vinculada à questão da produção de energia elétrica, desde as últimas décadas do século XX, assume novos contornos no século XXI, em função da constatação do processo de aquecimento global: o foco agora se desloca para a escassez hídrica nas próximas décadas, dado que uma melhor qualidade de vida pressupõe um meio ambiente ecologicamente equilibrado.

A poluição causada pelo aumento do uso de combustíveis fósseis e a utilização desordenada dos recursos hídricos vêm comprometendo a qualidade da água para o consumo humano. O crescimento demográfico, o desmatamento e o crescimento urbano sem planejamento multiplicaram os usos da água e provocaram um aumento em sua demanda, diante de uma oferta inelástica de água.

Dessa forma, o recurso deixa de ser interpretado como um bem comum, pois o balanço de sua disponibilidade e de suas demandas indica uma situação de escassez, não obstante a água ser um bem econômico e um recurso estratégico essencial ao desenvolvimento econômico e social.

Analisando-se as diferentes formas de apresentação, observa-se que uma expressiva parcela - 97.5\% - da água na Terra é salgada, referente a mares e oceanos; apenas os outros $2.5 \%$ correspondem à água doce, mas, boa parte pode ser considerada indisponível para alguns usos, já que provêm das distantes calotas polares e glaciais. (REBOUÇAS et al., 1999). Portanto, resta uma parcela de 0,8\% de água doce, correspondendo às águas terrestres superficiais e subterrâneas.

O Brasil, como os demais países da América Latina, não se encontra entre os mais afetados pela escassez da água, contando com $12 \%$ das reservas de água doce e algumas das maiores bacias hidrográficas do mundo - dos rios Amazonas, Paraná e São Francisco, além da reserva hídrica do Aquífero Guarani, submerso em territórios do Brasil, Argentina, Paraguai e Uruguai. (ANA, 2014). 
Observa-se, contudo, que essa abundância convive com a escassez que ocorre no semiárido nordestino, por exemplo. Na verdade, o problema brasileiro refere-se à má distribuição da água, configurando um quadro de desigualdade ambiental, além da poluição dos rios, que compromete a sua qualidade. Diferentemente dos países mais impactados, as questôes cruciais que atingem a população sul-americana não dependem da natureza, mas da ação humana.

O episódio da bacia do Rio Doce, em Minas Gerais, ilustra essa situação, que acabou redundando num crime ambiental de proporções dramáticas, sem falar em outros de menor repercussão causados por rompimentos de barragem.

$\mathrm{Na}$ produção de alimentos no mundo, o Brasil é um grande gerador de proteína animal e, segundo estimativas, atingirá o primeiro lugar no ranking até 2020. O país é um grande exportador de carne bovina, suína e de frango, já sendo rotulado com o "frigorífico do mundo": calcula-se que 1/3 da carne total consumida é de origem brasileira (Palhares, 2012).

Vale lembrar que a agricultura, por conta da irrigação, e o consumo da carne, fazem uso de $25 \%$ de toda a água do mundo. A título de exemplo, tem-se que é preciso mais de 15 mil litros de água para produzir um quilo de carne bovina a mais para servir como alimento aos humanos. De acordo com o Relatório da Organização Mundial de Saúde (OMS), divulgado em 2015, diminuir o consumo de carne é uma ação importante para a preservação da água.

Em função da oferta hídrica regional, cabe discutir o papel estratégico e regional da água no século XXI, de forma a garantir açôes visando segurança ambiental e o desenvolvimento econômico.

A questão da alocação da água ganha importância em função da sua escassez, uma vez que a concorrência entre os usos pela agropecuária, indústria e domicílios requer mecanismos adequados de gestão.

O Brasil obteve melhorias na gestão dos recursos hídricos desde a adoção da Lei da Política Nacional de Recursos Hídricos, em 1997, e da criação da ANA Agência Nacional da Água, em 2000, definindo as bases de uma governança integrada dos recursos hídricos, em contraste com o modelo de desenvolvimento centralizado e tecnocrático do governo militar. (OECD, 2015).

Todavia, a imagem de "abundância de água" no Brasil, de certa forma, acaba prejudicando o enfrentamento das questôes hídricas por parte das autoridades responsáveis, mascarando as reais necessidades de sua melhor alocação. 
A institucionalização de instrumentos econômicos de gestão ambiental surge como solução para o ajustamento do consumo social da água, de forma a se planejar os níveis de escassez relativa do recurso.

\section{A ESCASSEZ MUNDIAL DA ÁGuA}

Através dos tempos, os usos múltiplos e conflitantes da água vêm provocando uma diminuição na sua disponibilidade, em diversas regiões e países, trazendo preocupações com a questão da escassez, além dos problemas recorrentes de degradação e poluição ambiental.

O despejo de resíduos líquidos e sólidos em rios, lagos e represas e a destruição das áreas alagadas e das matas de galeria vêm causando uma progressiva deterioração e grandes perdas em quantidade e qualidade da água. A perspectiva de uma crise da água, a partir do aumento populacional, da crescente urbanização e das demandas sobre os recursos hídricos superficiais e subterrâneos, entre outras causas, compromete o desenvolvimento e é um agravante para as desigualdades regionais. (TUNDISI, 2011).

Em função das disparidades climáticas, as águas doces não estão distribuídas de forma regular, o que causa uma distribuição mundial da água desigual, que acaba exigindo estratégias de intervenção, tais como: a construção de reservatórios, o uso excessivo de águas subterrâneas e importação e transposição de águas entre bacias hidrográficas.

A Tabela 1 apresenta uma classificação de países segundo a sua disponibilidade de água por habitante.

Tabela 1 Países com maior e com menor disponibilidade de água per capita no mundo $\left(m^{3} / h a b\right)$.

\begin{tabular}{|l|l|c|}
\hline \multirow{4}{*}{ Países com mais água } & \multicolumn{1}{|c|}{ País } & m $^{3}$ /habitantes \\
\cline { 2 - 3 } & Guiana Francesa & 812.121 \\
\cline { 2 - 3 } & Islândia & 609.319 \\
\cline { 2 - 3 } & Suriname & 292.566 \\
\cline { 2 - 3 } & Congo & 275.679 \\
\hline \multirow{4}{*}{ Países com menos água } & Kuwait & 10 \\
\cline { 2 - 3 } & Faixa de Gaza & 52 \\
\cline { 2 - 3 } & Emirados Árabes & 58 \\
\cline { 2 - 3 } & Ilhas Bahamas & 66 \\
\hline
\end{tabular}

Fonte: Unesco (2003) 
Em que pese uma distribuição espacial desigual dos recursos hídricos no território brasileiro, o Brasil ocupa a 25a posição entre os países do mundo com maior disponibilidade hídrica por habitante, o que indica uma situação aparentemente confortável, quando comparada aos valores dos demais países informados pela Organização das Naçōes Unidas (ONU, 2003).

De acordo com a pesquisa coordenada pelo professor holandês Arjen Hoekstra (2013), pelo menos dois terços da população mundial vivem em áreas que sofrem com forte escassez de água em algum período do ano. Estima-se que 4,0 bilhões de pessoas vivem em escassez de água durante um mês do ano; 2,9 bilhões, durante 4 meses; 1,9 bilhão durante 6 meses e 500 milhóes, o ano todo.

O Mapa1 mostra a falta de água por período no mundo. Observa-se que as áreas em verde, que correspondem às regiōes que não passam nenhum mês em situação de escassez, coincidem com as grandes florestas, como a Amazônica, a África Central, a Indonésia, o norte da Europa e a Rússia.

Mapa 1 Quantidade de meses que cada região enfrenta escassez de água.

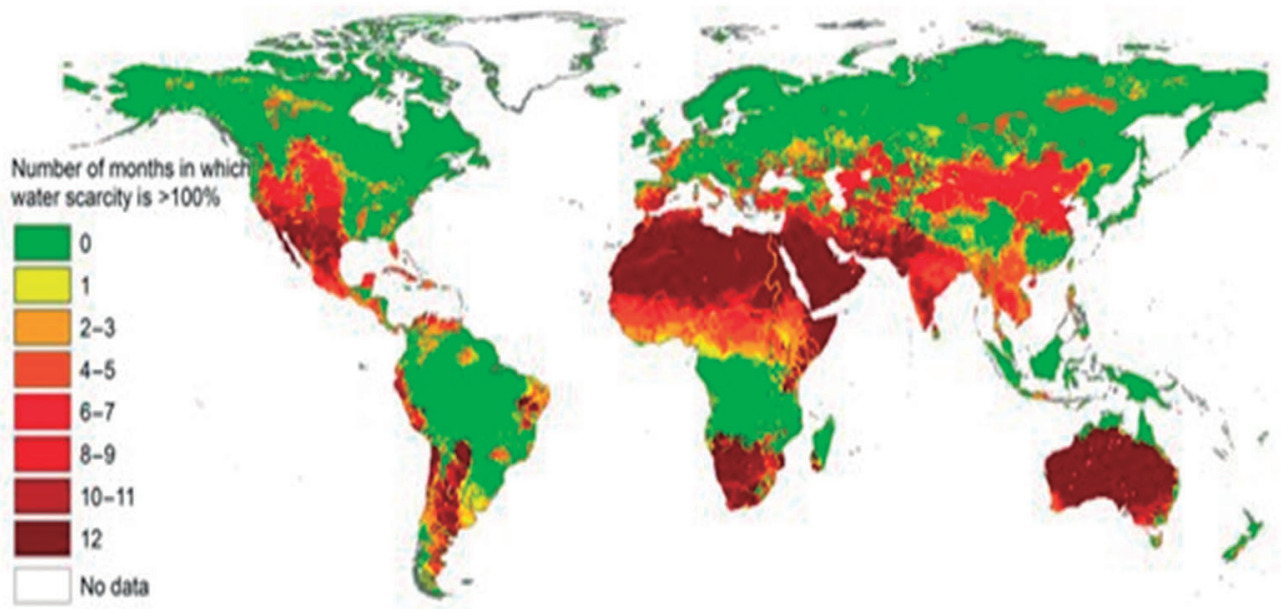

Fonte: Sadoff et al., 2015

Os efeitos na qualidade e na quantidade da água disponível, relacionados com o rápido crescimento da população mundial, com tendência à concentração em megalópoles, ocorrem em diversas partes do mundo. Dados do Fundo das Naçōes Unidas para a Infância (Unicef) e da Organização Mundial da Saúde (OMS) revelam que quase metade da população mundial (2,6 bilhões de pessoas) 
não conta com serviço de saneamento básico e que uma em cada seis pessoas (cerca de 1,1 bilhão de pessoas) ainda não possui sistema de abastecimento de água adequado.

As projeções da Organização das Nações Unidas indicam que, se essa tendência continuar, em 2050, mais de $45 \%$ da população mundial estará vivendo em países que não poderão garantir a cota diária mínima de 50 litros de água por pessoa. Com base nestes dados, em 2000, os 189 países membros da ONU assumiram como uma das metas de desenvolvimento do milênio reduzir à metade a quantidade de pessoas que não têm acesso à água potável e saneamento básico até 2015.

Observa-se que, mesmo para países que dispõem de recursos hídricos abundantes, como o Brasil, há uma ameaça de crise, uma vez que as reservas de água potável estão diminuindo, tendo como principais causas: o crescente aumento do consumo, o desperdício e a poluição das águas superficiais e subterrâneas por esgotos domésticos e resíduos tóxicos, provenientes da indústria e da agricultura.

Nessa perspectiva, ressalta-se a importância da preocupação premente na conservação dos recursos hídricos do planeta, bem como o planejamento de ações necessárias para garantir o seu consumo sustentável, e uma governança que priorize as necessidades das populações.

\section{GESTÃO DA ÁGUA NO BRASIL}

Reforçando o que já foi dito, o Brasil detém $12 \%$ da disponibilidade de água doce do mundo - o que torna a água um recurso comparativamente abundante em relação a outros países. Além de possuir o maior rio do mundo em vazão, o Rio Amazonas, conta também com dois grandes e representativos aquíferos do mundo, o Guarani e o Alter do Chão.

O Aquífero Guarani é o maior manancial de água doce subterrânea transfronteiriço do mundo, ocupando uma área de 1,2 milhões de $\mathrm{km}^{2}$, distribuída por quatro países, sendo que $71 \%$ concentram-se no Brasil, 19\% na Argentina, 6\% no Paraguai 6\% e 4\% no Uruguai, respectivamente. Indubitavelmente, quem domina a água, possui riqueza e força política. Assim, é grande a cobiça por parte de empresas e governos estrangeiros pela disputa do aquífero. (GUIMARÃES, 2006).

Os recursos hídricos são desigualmente distribuídos no território brasileiro: enquanto os estados nordestinos são predominantemente semiáridos, a região 
hidrográfica amazônica concentra cerca de $80 \%$ da disponibilidade hídrica - e é justamente onde se encontram as menores taxas de urbanização e densidade demográfica, bem como valores reduzidos de demandas consuntivas ${ }^{2}$.

Essa distribuição desigual não é incomum em países de grandes dimensões como o Brasil, mas oferece maiores desafios para a gestão dos recursos hídricos.

As questões hídricas afetam as regiōes brasileiras de diferentes formas: por escassez, por poluição urbana e industrial da água, pelo acesso aos serviços de abastecimento de água e saneamento. A Tabela 1 apresenta a disponibilidade de água por região, em termos proporcionais.

Tabela 1 Distribuição proporcional da disponibilidade de água por região (\%).

\begin{tabular}{|l|c|}
\hline \multicolumn{1}{|c|}{ Região } & Disponibilidade (\%) \\
\hline Norte & 68 \\
\hline Centro-Oeste & 16 \\
\hline Sul & 7 \\
\hline Sudeste & 6 \\
\hline Nordeste & 3 \\
\hline
\end{tabular}

Fonte: ANA (2014).

Observa-se que a região Nordeste é a que possui menor disponibilidade hídrica; ocorre que esse recurso encontra-se mal distribuído também dentro da região, concentrando-se mais nas áreas litorâneas da Zona da Mata e também no Meio Norte. Historicamente, uma boa parte da região Nordeste, principalmente a chamada região do Polígono das Secas, apresenta secas que se sucedem ciclicamente. Ou seja, no semiárido existem áreas que merecem particular atenção, classificadas como de elevado risco hídrico, nas quais se observam precipitação média anual inferior a $700 \mathrm{~mm}$, índice de aridez inferior a 0,35, indicando regiōes mais críticas no balanço precipitação-evapotranspiração, ausência de sistemas aquíferos sedimentares, que representariam potencial fonte de suprimento e de segurança hídrica para o abastecimento, ausência de rios perenes com elevado porte ou com grande capilaridade, que também significariam fator de segurança hídrica.

2 Referentes aos usos que retiram a água de sua fonte natural, tais como irrigação, dessedentação animal, abastecimento público, processamento industrial. 
Dentro desse contexto, uma das práticas implementadas para garantir a oferta de água na região Nordeste é a construção de açudes, que desempenham relevante papel na gestão de recursos hídricos pela capacidade de estocar e atender a diversos usos da água, consuntivos ou não.

As regiōes Sul e Sudeste contam, igualmente, com uma disponibilidade limitada, com altos níveis de consumo de água. Recentemente, a falta de água também afetou a região Sudeste e, em maior grau, a região metropolitana de São Paulo, provocando uma grave crise hídrica, que afetou mais de 20 milhões de pessoas.

O conhecimento da distribuição espacial da oferta de água é de fundamental importância para determinar o balanço hídrico nas bacias brasileiras.

A gestão hídrica passou por reformas substantivas, a partir da Política Nacional de Recursos Hídricos de 1997, que definiu os princípios e diretrizes básicos, e a criação da Agência Nacional da Água - ANA, em 2000, representando um marco na condução do processo de gestão.

Quadro 1 Disponibilidade hídrica per capita para cada Estado brasileiro (em m³/hab/ano).

\begin{tabular}{|l|l|l|}
\hline $\begin{array}{c}\text { Disponibilidade } \\
\text { hídrica } \\
\text { Per capita }\end{array}$ & $\begin{array}{c}\text { Classificação } \\
\text { da disponibilidade }\end{array}$ & \multicolumn{1}{c|}{ Estados da federação } \\
\hline Mais de 20.000 & Riquíssima & $\begin{array}{l}\text { Acre, Amazonas, Amapá, Goiás, Mato Grosso, } \\
\text { Mato Grosso do Sul, Pará, Rio Grande do Sul, } \\
\text { Rondônia, Roraima, Tocantins. }\end{array}$ \\
\hline Mais de 10.000 & Rica rica & $\begin{array}{l}\text { Maranhão, Minas Gerais, Santa Catarina, } \\
\text { Paraná. }\end{array}$ \\
\hline Mais de 5.000 & Adequada & Espírito Santo e Piauí \\
\hline Mais de 2.500 & Pobre & $\begin{array}{l}\text { Alagoas, Ceará, Distrito Federal, Rio de Janeiro, } \\
\text { Rio Grande do Norte, Sergipe. }\end{array}$ \\
\hline Menos de 2.500 & Crítica & Paraíba, Pernambuco \\
\hline Menos de 1.500 & & \\
\hline
\end{tabular}

Fonte: ANA (2014).

Em termos de disponibilidade hídrica per capita, existem modalidades de distribuição classificadas pela OMS, em diversos locais do planeta, inclusive no território nacional, que consideram regiōes abundantes em água aquelas que disponibilizam volumes superiores a $20 \mathrm{mil} \mathrm{m}$ /pessoa/ano, passando pelas classes 
intermediárias, que disponibilizam cerca de $5 \mathrm{mil} \mathrm{m} 3 /$ pessoa/ano, até as portadoras de situações críticas, que disponibilizam volumes inferiores a $1.500 \mathrm{~m} 3 /$ pessoa/ano.

O Quadro I apresenta o ordenamento dos Estados conforme essa disponibilidade, medida em $\mathrm{m}^{3}$ de água para cada habitante no período de um ano. Observando-se os dados, é fácil perceber como o recurso se encontra mal distribuído pelo território brasileiro.

A questão da alocação da água ganhou visibilidade através do problema da sua escassez. A concorrência entre os diferentes usos, como agricultura, indústria e domicílios, requer mecanismos adequados para o gerenciamento de soluções, uma vez que a energia hidrelétrica é a principal fonte de energia no Brasil, sendo que 87.1\% da geração de eletricidade provêm de fontes renováveis. (OECD, 2015).

Da retirada total de água no Brasil, a agropecuária participa com $54 \%$ da captação, o abastecimento humano com 25\% e a indústria com 17\% (ANA, 2014). Essas participações diferem entre as regiōes, refletindo as diferenças nos padrões climáticos e socioeconômicos entre os Estados.

A descarga de efluentes domésticos é o principal problema que afeta a qualidade das águas superficiais (MMA, 2008), pois apenas 48\% dos esgotos domésticos são coletados e 39\% são tratados (IBGE, 2010).

Outros grandes poluidores que afetam a qualidade da água em todas as regiões hidrográficas incluem os efluentes industriais, de mineração, descargas difusas de drenagem do solo urbano e agrícola, e a deposição de resíduos sólidos.

A água tornou-se um fator limitante para o desenvolvimento econômico, políticas de saúde pública e bem-estar no Brasil. Os riscos de inundações, escassez e poluição podem aumentar de forma considerável, como resultado dos impactos combinados de fatores inter-relacionados de crescimento econômico, mudanças no uso do solo, mudanças demográficas e climáticas.

Ao mesmo tempo, uma abordagem estratégica para a gestão dos recursos hídricos poderia desempenhar um papel importante, ao maximizar o bem-estar econômico e social de forma equitativa, sem comprometer a sustentabilidade dos ecossistemas - a gestão coordenada da água, do solo e dos recursos relacionados. (OECD, 2015).

Por outro lado, a concorrência pelo acesso à água também envolve questôes de equidade, cabendo considerar o papel da água nos programas sociais de combate à pobreza, em situações de escassez e de alocação dos riscos. 
Os Estados do centro e do sul demandam grandes quantidades de água para irrigar as lavouras: arroz, milho, feijão, soja, cana-de-açúcar, frutas; o sudeste do Brasil enfrenta a competição pelo acesso ao recurso, devido à rápida industrialização e urbanização. As atuais questôes de seca e escassez no Sudeste, as inundações no Norte e as secas no Nordeste ilustram os desafios potenciais que o país poderá vir a enfrentar.

Dessa forma, é preciso implementar ações que assegurem o crescimento econômico, de maneira que as secas não afetem os programas sociais de combate à fome, e que os riscos à saúde devido a inundações sejam minimizados.

A qualidade da água está ameaçada pela poluição, nas áreas industriais das regiōes costeiras, e pelo lançamento de efluentes não tratados nas cidades, que sofrem pressões demográficas e econômicas. Em partes do sul e sudeste do país, a enorme descarga de água servida, urbana e industrial, prejudica a qualidade da água. Os estados de São Paulo, Rio de Janeiro e Minas Gerais vêm enfrentando escassez quantitativa e qualitativa de água. Em outras regiões, a poluição difusa causada pela agricultura também está deteriorando a qualidade da água, provocando restrições na disponibilidade para outros usos.

Uma gestão coerente e uma regulamentação rigorosa são indispensáveis para se evitar que a deterioração da qualidade da água venha causar fortes impactos sobre a disponibilidade do recurso, sobre o meio ambiente e sobre a saúde.

É necessário também que haja coerência de política entre o saneamento e a gestão dos recursos hídricos, pois a água contaminada não pode ser utilizada posteriormente, a menos que seja submetida a um processo de tratamento, envolvendo novos custos.

A gestão de recursos hídricos conjugada à prestação dos serviços de saneamento e abastecimento de água é indispensável para se conseguir soluções efetivas para enfrentar as secas no Nordeste, a crescente demanda para irrigação e energia hidrelétrica no Brasil Central, além da poluição da água nos grandes centros urbanos.

Por outro lado, é importante que as desigualdades no acesso a serviços de abastecimento de água e esgotamento sanitário sejam resolvidas. A cobertura de abastecimento de água nas áreas urbanas é quase total (99.7\%), enquanto que 15\% da população rural permanecem sem acesso a uma fonte de água tratada (Banco Mundial, 2013). Grande parte dos 12.8 milhões de domicílios que permanecem sem acesso concentra-se nas regiões Norte e Nordeste, onde apenas 45\% e 69\% 
deles, respectivamente, contam com água encanada. No Nordeste, o abastecimento de água é prejudicado devido às condições do clima semiárido, que predominam na região, enquanto o baixo acesso à água na região Norte, com recurso abundante, pode ser atribuído, principalmente, à falta de infraestrutura (MCidades, 2014).

Em relação à questão do esgoto, as taxas de acesso a melhores instalações aumentaram de $66.8 \%$ para $81.3 \%$, entre 1990 e 2012 . As taxas de acesso permanecem significativamente mais elevadas nas áreas urbanas (87\%) do que nas rurais (49.2\%) e decrescem nas periferias urbanas de baixa renda e nas favelas. (Banco Mundial, 2013).

Mesmo contando com melhor infraestrutura, no sudeste do país, algo em torno de $15 \%$ dos domicílios não estão conectados à rede de esgotos; percentual que aumenta para 70\% na regiāo Norte. (MCidades, 2014).

Em relação a tratamento, apenas $68.8 \%$ do volume total de esgoto coletado recebe algum tipo de tratamento, em comparação aos 35.3\% em 2000, e aos 19.9\% em 1989. Apenas um terço dos municípios equipados com rede de coleta de esgoto possui tratamento. (MCidades, 2014).

O acesso à água no Brasil é um problema significativo para os domicílios de baixa renda e para os assentamentos precários. Nos grandes centros urbanos há necessidade de alternativas de abastecimento público de água, enquanto que nas zonas rurais o esgotamento sanitário se caracteriza pelo alto nível de precariedade. Estima-se que $10 \%$ dos brasileiros vivem em habitações sem acesso a uma rede de esgoto ou fossa séptica, enquanto $7 \%$ moram em habitações sem acesso à água encanada ou poços (MCidades, 2014).

A partir da observação da situação dos mananciais brasileiros, urbanos ou rurais, pode-se perceber que as ações de gestão dos recursos hídricos ainda não se mostraram suficientes para solucionar a crescente degradação das águas, não obstante a promulgação da Lei das Águas, em 1997.

$\mathrm{O}$ atual quadro de degradação do meio ambiente, provocado pelo uso inadequado dos recursos naturais, promovido pelas diversas atividades produtivas e pelas atividades cotidianas urbanas e rurais durante séculos, retrata a pouca preocupação com a sanidade ambiental, resultando em bacias hidrográficas poluídas, em maior ou menor grau, por receberem contínuas cargas de contaminantes, principalmente os esgotos urbanos, além de efluentes das atividades industriais, agropecuárias e de extração mineral, entre outras. (ANA, 2015). 
Nas áreas urbanas brasileiras, a crescente impermeabilização do solo e a canalização dos cursos d'água provocam maior escoamento superficial das águas pluviais e sua menor infiltração no subsolo, reduzindo as interações das águas superficiais e subterrâneas e rompendo os mecanismos de atenuação de cheias e secas. Por outro lado, áreas de risco, como encostas íngremes e planícies aluviais, são ocupadas, por falta opção, por populações de baixa renda, implicando, muitas vezes, em catástrofes de proporções dramáticas. Considere-se ainda, os efeitos da poluição hídrica sobre a saúde da população; estima-se que cerca de 70\% das doenças humanas sejam causadas por veiculação hídrica. (ANA, 2015).

Além de grandes investimentos, para corrigir esse quadro caótico e obter melhores resultados na manutenção da qualidade e quantidade dos recursos hídricos, pelo menos no longo prazo, é necessária a integração de sua gestão com outras políticas e ações setoriais. Assim, por exemplo, enquanto o setor de saneamento é o maior responsável pelos conflitos de uso dos recursos hídricos advindos de sua má qualidade, o setor de irrigação responde pelos maiores conflitos, resultantes da falta d'água em regiôes onde ela já é naturalmente escassa. No Brasil, estima-se que, no período 2010$2011,72 \%$ do consumo de água foram destinados à irrigação, 14\% ao abastecimento urbano, $9 \%$ ao setor industrial e 5\% a outros usos (DOMINGUES, 2012).

Não obstante esses números expressivos dos mananciais brasileiros, os usos múltiplos da água e a dependência da sociedade e dos ecossistemas em relação a ela vêm tornando os recursos hídricos cada vez mais escassos em certas regiões, pela sua falta, ou por conflitos de uso. A água escassa para as atividades básicas da vida humana acarreta diversos ônus, como a necessidade de buscá-la cada vez mais longe e, consequentemente, com custos cada vez maiores -, indicativos do valor econômico da água. (LANNA, 2008).

Numa visão prospectiva, quatro usos da água possuem potencial de conflito, pelo seu uso excessivo, ou pelas interferências que causam no regime hídrico, quais sejam: a agricultura irrigada, que é o maior usuário de água no País; a geração de energia elétrica, que, no Brasil, tem a base hídrica como preponderante e que, não obstante ser um uso não consuntivo, promove importantes alterações no regime hídrico; a navegação - outro uso não consuntivo, mas que demanda regimes hídricos com restriçôes aos usos anteriores; e o saneamento ambiental, ou, mais especificamente, a assimilação de esgotos pelos corpos de água, de cujo equacionamento depende a qualidade hídrica e sua adequação às demandas, em especial às relacionadas à segurança alimentar humana e animal (LANNA, 2008). 
Esses cenários demonstram que, se, por um lado, os usos múltiplos são, teoricamente, desejados, por outro, isso nem sempre se mostra viável na prática. $\mathrm{O}$ aumento da demanda por recursos hídricos em quantidade e qualidade adequadas, estimulado pelo contínuo crescimento da população e pela expansão das atividades econômicas - agravados pelas mudanças climáticas, que impõem a ocorrência cada vez mais frequente de eventos críticos, seja de abundância, seja de escassez de água -, vem dificultando a compatibilização dos diferentes usos, tendo como resultado conflitos nem sempre possíveis de administrar. Esse foi o argumento principal para a proposição de um novo modelo de gestão das águas no País, por meio da Lei das Águas. (ANA, 2015).

Em que pesem as recomendações necessárias, contidas na Lei das Águas, é preciso considerar a complexidade ambiental do Brasil, que agrega diferentes realidades, como, por exemplo, uma região como a Amazônia, onde há muita água; uma região semiárida, com pouca água, e uma região urbana, com águas poluídas.

A Secretaria Nacional de Saneamento Ambiental do Ministério das Cidades elaborou, em 2013, o Plano Nacional de Saneamento Básico, incluindo um conjunto de metas por região e por Estado para o período de 2014 a 2033. Mas, para se resolver de fato as crises existentes, é necessário que se faça uma revisão das práticas de governança da água no Brasil, visando um melhor uso da infraestrutura e dos recursos financeiros disponíveis.

$\mathrm{Na}$ verdade, observa-se que a estrutura institucional diferenciada de recursos hídricos reflete a distribuição da água e o desenvolvimento econômico desigual do Brasil.

A prioridade de gestão dos recursos hídricos foi dirigida para as regiōes mais problemáticas, abrangendo o Sudeste e Nordeste do Brasil. A mudança climática afeta a disponibilidade hídrica e a demanda de água, envolvendo uma maior análise dos impactos e levando-se em conta os eventos hidrológicos extremos e a mudança dos padrões pluviais, que irão exigir a construção de infraestrutura apropriada para armazenar água ou para proteger contra seu excesso.

As consequências das mudanças climáticas sobre a disponibilidade e a demanda hídrica no Brasil apresentam um grau de incerteza que deve ser levado em consideração, uma vez que afetam a gestão dos recursos hídricos. As questôes resultantes das mudanças climáticas não irão se restringir ao uso da água por setores econômicos concorrentes, mas também afetarão a saúde, dado que, nessa situação, as doenças de veiculação hídrica podem se agravar seriamente. 


\section{GESTÃO (IN)SUSTENTÁVEL DA ÁGUA}

Nas últimas décadas, os conflitos pela posse ou domínio das águas vêm ganhando maior visibilidade no Brasil e no mundo. Provavelmente, por isso, a água tenha sido um dos primeiros recursos naturais a ter seu uso normatizado - ainda que sem um caráter social ou ambiental, mas econômico -, antes, inclusive, da legislação ambiental, vigente no Brasil a partir da segunda metade do século XX.

Com a aceleração do processo de industrialização e da crescente urbanização, e os consequentes efeitos da poluição e dos conflitos pelo uso das águas, foi se tornando cada vez mais necessário um maior controle no uso dos recursos ambientais, em geral, e dos recursos hídricos, em particular. Vale lembrar a predominância dos interesses do setor elétrico junto aos recursos hídricos, muitas vezes, inclusive, em detrimento de outros usos.

A partir da Conferência Internacional sobre Água e Meio Ambiente, em Dublin, 1992, um novo "paradigma” passou a gerir a política da água; convertida em recurso econômico, a água poderia vir a ser utilizada de maneira mais eficiente, melhor conservada enquanto recurso escasso, tornada mais acessível e ecologicamente melhor preservada. (HOERING, 2006).

Examinando-se a trajetória de atuação do Banco Mundial, observa-se que até o final dos anos 1980, ele apoiava os governos através de financiamento e gestão do setor água, incluindo a ampliação da infraestrutura hídrica para a geração de hidroeletricidade. Mas, a partir de 1993, o Banco Mundial passou a adotar uma concepção integrada de gerenciamento, reformulando a ação político-institucional, de forma a privilegiar o setor produtivo. A introdução de instrumentos econômicos na regulação da água enquanto bem comercializável no mercado levaria à privatização da gestão e do abastecimento de água. Ressalte-se a retirada do Estado para funções estratégicas da regulação da água, desde meados dos anos 1990, quando, por ação do Banco Mundial, em muitos países, reformas mais ou menos abrangentes foram sendo realizadas, nesse sentido.

A partir desse período, o Banco Mundial vem demonstrando uma grande preocupação em estabelecer direitos referentes à água e mecanismos de gestão, visando incentivar o aumento da eficiência no uso da água na agricultura, melhorar a qualidade da água e pesquisar os efeitos das mudanças climáticas sobre os recursos hídricos - ações estas que, em sua ótica, estariam atraindo investimentos privados para o setor água (ROSEGRANT; RINGLE, 2004). 
O aparelho ideológico propagandeia que a crise da água se constitui em séria ameaça à produção de alimentos, à saúde humana, à nutrição e ao meio ambiente, recomendando investimentos seletivos em tecnologia de ponta e infraestrutura que incrementem a conservação e o uso eficiente de água.

\section{CONSIDERAÇÕES FINAIS}

Uma análise acerca da gestão das águas, deve ter como pressuposto que a água, além de recurso natural limitado dotado de valor econômico, possui também valor social e ambiental.

Entre as medidas possíveis para uma gestão sustentável das águas, sugere-se: melhor integração da gestão hídrica com outras políticas e ações setoriais, como as de saneamento; diminuição das perdas d'água em tubulações precárias e ligações clandestinas; redução do desmatamento em todos os biomas do País; ações de reflorestamento de áreas degradadas e ambientalmente sensíveis; melhor controle do uso do solo urbano; tratamento adequado dos efluentes industriais e esgotos domésticos; incentivo a sistemas de irrigação com menor gasto de água; conscientização da população quanto à necessidade de redução de desperdício de água; maior discussão quanto ao conflito de interesses público e privado na prestação dos serviços de saneamento; e melhor planejamento da implantação, operação e manutenção da infraestrutura hídrica, entre outros. (ANA, 2015).

Considerando-se que, embora a água seja a substância mais abundante do planeta, apenas uma pequena parte do total existente no mundo é viável, atualmente, à captação e ao consumo. Dessa forma, a contaminação da água, ocasionada pelo uso inadequado dos recursos hídricos e pela concentração demográfica, pode torná-la um recurso escasso, configurando um problema econômico. A produção capitalista favorece a expansão predatória dos recursos ambientais, visando atender ao consumo, até o ponto em que encontra limites físicos concretos, gerando a escassez de recursos, como ocorre com a água.

Nesse contexto, a água assume valor econômico e passa a ser encarada como um bem econômico, capaz de assegurar uma posição estratégica para aqueles países que forem detentores de fontes de água.

Com base nesse fato, a água passa a ser reconhecida como mercadoria e quem a detém terá a preocupação de preservá-la e conservá-la como recurso; sendo escassa, terá alto valor no mercado. Ao manter a qualidade, os países que tiverem 
abundância de água passarão, automaticamente, a contar com mercado garantido. Isso proporcionará oportunidade de negócios para países, como o Brasil, que detêm grandes quantidades de água.

Em suma, embora possa parecer uma incongruência falar em escassez em um planeta que tem $70 \%$ de sua superfície coberta por água, essa é a tendência que se delineia para os próximos anos, quando se espera que ocorra um aumento ainda maior no consumo, devido à demanda e ao crescimento populacional acentuado e desordenado, principalmente nos grandes centros urbanos. Nesses termos, uma conscientização para o problema da água deverá ganhar espaço nas discussões mundiais em torno da preservação ambiental e do combate à fome e à mortalidade infantil.

\section{REFERÊNCIAS}

AGÊNCIA NACIONAL DE ÁGUAS. (Brasil). Conjuntura dos recursos hidricos no Brasil: regiōes hidrográficas brasileiras. Edição Especial. Brasília: ANA, 2015.

AGÊNCIA NACIONAL DE ÁGUAS (Brasil). Conjuntura dos recursos hidricos no Brasil: 2014/Agência Nacional de Águas. Brasília: ANA, 2014.

BANCO MUNDIAL. Relatório Anual de 2013. In: https://openknowledge.worldbank. org/bitstream/handle/10986/16091/9780821399422PT.pdf. Acesso em: 14/03/2017.

DOMINGUES, A. F. Os instrumentos da Política Nacional de Recursos Hidricos. Palestra ao Centro de Estudos e Debates Estratégicos (Cedes). Brasília, Câmara dos Deputados, 22/08/2012. Disponível em: http://www2.camara.leg.br/a-camara/altosestudos/temas/ temas-2013-2014/uso-multiplo-das-aguas/uso-multiplo-das-aguas. Acesso em: 02/04/2017.

GUIMARÃES, L. R. Aquífero Guarani: integração e destaque da América Latina no cenário mundial. Anais do III Congresso da Associação Latino-americana de Ciência Política. Campinas; UNICAMP, 4-6 set., 2006.

HOEKSTRA, A. Y. The Water Footprint of Modern Consumer Society, Routledge, London: 2013.

HOERING, U. Der Markt als Wassermanager: Aufbau Eines Neue Wasser Regime Durch die Weltbank. Peripherie, ano 26, n. 101/102, p. 21-42, 2006.

IBGE. Censo 2010. Brasília: 2010. In: http://censo2010.ibge.gov.br. Acesso em: 20/03/2017.

LANNA, A. E. A economia dos recursos hídricos: os desafios da alocação eficiente de um recurso (cada vez mais) escasso. In: Revista Estudos Avançados: dossiê água. Instituto de Estudos Avançados da USP. v. 33, n. 63, maio-ago. 2008.

MINISTÉRIO DAS CIDADES. Secretaria Nacional de Saneamento Ambiental SNSA. Sistema Nacional de Informaçôes sobre Saneamento: Diagnóstico dos Serviços de Água e Esgotos. 2013. Brasília: SNSA/MCIDADES, 2014. In: http://engineering.columbia.edu/ files/engineering/design-water-resource07.pdf. Acesso em: 22/03/2017. 
MMA. Relatório de gestão. Brasília: Instituto Chico Mendes de conservação da biodiversidade. ICMBio, 2008. In: http://www.icmbio.gov.br/portal/images/stories/oque-somos/RelatorioGestaoICMBio_2008web.pdf. Acesso em: 15/04/2017.

OECD. Governança dos Recursos Hídricos no Brasil, OECD Publishing, Paris: 2015 In: http://dx.doi.org/10.1787/9789264238169-pt. Acesso em: 10/03/2017.

OMS. Relatório Mundial de Envelhecimento e saúde. 2015. In: http://sbgg.org.br/wp-content/ uploads/2015/10/OMS-ENVELHECIMENTO-2015-port. pdf. Acesso em: 15/03/2017.

ONU. Relatório Mundial das Nações Unidas sobre o Desenvolvimento de Recursos Hídricos. Paris, 2003. In: http: www.wateryear2003.org. Acesso em: 01/03/2017.

PALHARES, J. Pegada hidrica e a produção animal. In: http://www.cppse.embrapa.br/ sites/default/files/principal/. Acesso em: 10/03/2017.

REBOUÇAS, B. B., CUNHA. A., BRAGA B. (Org.). Águas doces no Brasil: capital ecológico, uso e conservação. São Paulo: Escrituras, 1999.

SADOFF, C.W., HALL, J.W., GREY, D., AERTS, J.C.J.H., AIT-KADI, M., BROWN, C., COX, A., DADSON, S., GARRICK, D., KELMAN, J., MCCORNICK, P., RINGLER, C., ROSEGRANT, M., WHITTINGTON, D., WIBERG, D. Securing Water, Sustaining Growth: Repor to the GWP/OECD Task Force on Water Security and Sustainable Growth, U.K: University of Oxford, 2015. In: http://www.water.ox.ac.uk/ wp-content/uploads/2015/04/SCHOOL-OF-GEOGRAPHY-SECURING-WATERSUSTAINING-GROWTH-DOWNLOADABLE.pdf. Acesso em: 15/03/2017.

TUNDISI, J.G. TUNDISI, T. M.T. Recursos hídricos no século XXI. São Paulo: Oficina de Textos, 2011. 
